\title{
Fashion Films and Net-aesthetics
}

\author{
Simonetta Buffo \\ Università Cattolica del Sacro Cuore and Istituto Marangoni, Milan, Italy
}

\begin{abstract}
Fashion Film is the last communication tool in fashion market, that was born for the Web about 20 years ago, but in these last 10 years it has increased its diffusion and its expressive potentiality definitely and we think that it is designed to influence the communication in other markets. Nowadays Fashion Films are reinforcing the power of fashion images, building up new brand experiences for net-consumers: they are painting new worlds for fashion brands thanks to the old cinematographic language mixed to recent Internet logics. Starting from this observation, our main question was: Can we talk about a new fashion net-aesthetics for these new fashion tales? Using a semiotics approach, this study investigates how Fashion, Cinema and the Net come together, producing new aesthetics, with new languages and new imaginary in fashion. The result can be really visionary.

Keywords: fashion film, fashion language, fashion codes, fashion semiotics, film languages, fashion photography, fashion images, fashion net-aesthetics, fashion aesthetics, fashion net-imaginary, fashion imaginary
\end{abstract}

\section{Fashion Advertising and Fashion Tales}

In last years Fashion Brands have matured a great ability and awareness in creating new kinds of Fashion Tales: indeed these stories picture imaginary worlds, that look very different in form and content compared to those of the past, beginning with their protagonists, the women models and ending to new communication format.

In the 1990s, top super models were gifted with a strong personality, which was further enhanced on the runaway and showed off on the advertising campaigns. Their exclusive look, classical beauty and lifestyle conveyed a shimmering luxury, which was a symbol of perfection. In contrast, current models are often anonymous, hardly ever recognisable and very pale, with short professional careers and they do not represent classical beauty.

Obviously, the exceptions are those top models who have been able to embody fashion. In the past Veruska and Twiggy were successful in this, whereas today Eddie Campbell and Georgia May Jagger or Kristen Steward and Cara Delevigne appear to have this quality. But the extraordinary phenomenon of top super models in the 1990s consisted of a solid block of divas who symbolised women who were successful in their public and private lives, and constituted an aspirational model of perfection and luxury.

It may be a paradox, but current models do not aim to be liked as women, rather only as models. Often such women seem to have a talent for appearing like ghosts, or they represent strong and pugnacious women.

Such a huge difference in the choice of fashion's protagonists is closely linked to the background values attributed to fashion production, which also differ in the two periods being compared. Indeed, in the 1990s, the

Simonetta Buffo, Academic, Faculty of Communication and Sociologic Studies (COMeS), Department of Sociology, Università Cattolica del Sacro Cuore and Istituto Marangoni. 
value assigned to the object was desire and its multiple narrative interpretations. Such desire translated the aspirational mood into a consumption model. In ancient Latin, desiderare (which literally means desire) meant carefully observing the stars. It suggests aspiration to something undefined, which is appealing, as it stands above things available in everyday life. This is why the openness of desire overcomes any defined reality. Desire has no space, time or place. The advertising communication object of fashion in the 1990s was the concrete representation of women's desires and it became the final aim of women's aspirations, which is why it acquired almost a magical halo, or was like an amulet that safeguards everyday life and confers strength and safety. Back in those years, the object to which value was attributed (be it a dress, a pair of shoes or a handbag) became an object of veneration, as if it was a talisman. The object of veneration in fashion, often presented in far-away or unreal contexts, characterises the person who wears it by giving her a stronger personality and unique quality, as if it was a magic tool. The object of veneration in fashion declaims its distance from the real world, a distance that becomes synonymous with exclusivity.

A gradual but significant change has been perceived since the 2000s. Authenticity is the new protagonist of Fashion Tales, the notion of being as opposed to seeming. The dress in fashion advertising has become an expression of a way of being that is not rigidly defined and built by the image, but represents mediation between oneself and society in an ever-changing reality that is by definition eclectic, multifaceted, fleeting and full of interpretations.

Let us try to better understand what we mean in fashion by being as opposed to seeming. If fashion in the past worked on appearances, it currently represents the chance to express a way of being without mediation or compromise. Consequently, in the new Fashion Tales, fashion is often represented as a sort of dreamy Eden, where anybody can be either who they are or who they want to be without fear of social judgement. Indeed, fashion is interested in strong personalities, who do not always represent icons of beauty. Often, writers, musicians, rappers, artists, journalists, actors and models of the past are the new brand ambassadors of fashion.

It does not matter how you look, or your age, your sexuality, but it matters who you are, what you do and what "fights" you have fought.

Fashion brands tell stories about courage and authenticity by pushing interpretation limits beyond imagery. Designer labels create sets of wonderland where anything is possible, as in a dream or fantasy; fashion suggests behaving like Alice and bravely chasing after the White Rabbit in pursuit of a more authentic identity by winning over one's fears.

On the other hand, the elements of change in fashion communication reflect the new consumer and are aimed at the unique and clear goal of generating a bond as well as active participation on the part of the consumer by sharing values and impulses and, at the same time, by prompting possible interpretations among suggestions.

Today more than ever, it has become obsolete to use the persuasive power of advertising. First, the consumer is a more prepared, competent critic than before and is less willing to use know-how to solicit a brand, which is recognised as a business engine. Such consumers have developed a strong resistance to absorbing the content of an advertising message, which explains why there is no reason to talk about a target, such as a series of subjects who must be "hit" by communication actions. The second reason why we do not talk about advertising as a persuasive tool any more is that consuming is considered emotional experience and entertainment. Hence, the more advertising communication is like a game, the more effective it is, and fashion 
advertising is no exception. Thanks to the bold social and market revolution realised by the web and particularly by web 2.0 , today's consumer wants their subjectivity to be recognised, and emotions come first during each experience.

Escalas (2004) aimed to understand when the arguments of an advertising campaign work better. In summary, they assessed and compared self-referencing and common analytical thinking in advertising messages. The concept that is accepted today by more and more experts and lay people is that advertising communication is not, and must not be, informative. This may sound strange, as brands are born with the goal of differentiating one brand from another, by providing the consumer with clear, unique and distinctive benefits. Each brand has always been the expression of a point of difference. This is what advertisers have taught us. Today, this point of difference of a brand is not relevant to the rational zone; but it has a bearing on the emotional sphere.

The conclusions that Escalas drew in this article match the above-mentioned idea that consumers are carried away in a story by building hypothetical scenarios; hence, they cancel or tone down the effects of weak advertising arguments. A consumer's analytical thinking approach is strongly influenced by their personal experience and knowledge about a specific brand, so effective arguments must be definitely sound and well structured. According to the author, the fact that the consumer is carried away suggests strong affective responses and a low critical level, which is contrary to what happens with a more rational, thinking approach to the brand's message. This is in line with the semiotics theory of Eco, that the receiver of a message must be the co-author of the same message for the message to be complete and effective.

Escalas's conclusions present an interesting point: the importance of emotionally engaging a consumer is that the consumer is then freed from a rational mental structure and participates in an imaginary reality. Being emotionally involved is definitely one of the post-modern consumer's requests (Fabbris, 2007), but it is also the only chance today for a brand to make a consumer live a positive brand experience, by empathising with an individual who may become a consumer, and then to entice them to enter the brand's world.

Consequently, a brand must be made more "alive" through experiences that involve all individuals interested in it.

Today, the individual consumer is an active subject who must be engaged in a game that they know they can play. In fact, the consumer decides, which is why we have fashion short movies or fashion films that can only be watched online as a conscious and voluntary choice of the consumer and that comply perfectly with brand entertainment logic.

\section{Fashion Film: Creating a Net-imaginary}

Few markets understand the revolutionary range of the brand entertainment approach and the strength of the web. The fashion market, however, seems to be very interested in this new media and is aiming to find new solutions for creating fresh imagery for a brand.

Indeed, the Internet is a new way to connect with consumers. Consumers can write, watch, talk and listen to anybody and everybody on the Internet and also to the brand. This is why brand content is almost immediately out-dated; it must always be new. Being fast has become a must. New content is created constantly, sometimes without control by the brand. Reputation has become a new challenge for the brand that involves paying attention to what happens on the Internet.

Brands have new rules by which to contact people through the net. 
Probably the most interesting, revolutionary and avant-garde web solution in terms of creating brand imaginary is that of fashion movies. Indeed, fashion films reach similar targets that a (fashion) brand does by providing a communication strategy that accords with the new consumer:

\section{Involving instead of Persuading}

As stated before, fashion brands do not explain the features of their products through advertising campaigns: They don't try to persuade their public using a rational motivation. Fashion brands probably know that the post-modern consumers like to choose their purchases, making evaluations that are objective and precise, while brands have business goals and are not a credible source of information. Therefore, if consumers need information about a product or brand, they look on the specific consumers' blog. This novelty suggests a new role for communication in the branding process.

On the other hand, new consumers like to be involved in the brand and to be part of an imaginary world. Many new fashion images have the power to create strong feelings, fusing an emotional and irrational response. The consumer has large interpretative and imaginative spaces to explore. The more this world becomes close to the consumers' feelings, the more it will be perceived as the new Wonderland.

\section{Disclosing Instead of Declaiming}

Fashion brands in these short movies trace their own world to claim their uniqueness. The product may be the protagonist, but it often appears like a conceptual answer to a current way of life. Images in these frames are often unclear and may be mysterious and subjective, but never absolute. Consumers discover new territory in their mind by means of fashion brands, thanks to these images.

\section{Enjoying Instead of Selling}

Consequently, this Fashion Wonderland is something like a video game where consumers can lose themselves. Here, special heroes and heroines crowd the luxury market. The structure is mythological and works on people animated by universal virtues. In particular, in recent years, the most important value for fashion is that of the courage to be unique in a society that is always ready to judge and sentence. So, the set pictures are surreal and the real people in them have universal desires, passions and emotions. The union of fantasy and real life creates a fascinating, mysterious and dreamlike world.

\section{Innovating Instead of Repeating}

In the past, brand communication worked on repetition. The more a brand repeated its message, the more the consumer memorised the message. Nowadays, consumers do not like repetition, and brands are considered boring if they impose themselves in the old communicative way. So, brands must surprise and intrigue the consumer through continuous innovation. By creating new contact occasions with new solicitations brands can maintain the consumer's attention at a high level. Innovation has always been a must for business, particularly in the fashion market, but it is now the first condition of survival, and communication is a key tool.

Indeed Fashion film is a revolutionary strategic communication solution created by fashion.

\section{Fashion dot Movie: Birth of fashion net-aesthetics}

Our first step is to define exactly what fashion film means. A fashion film is a short movie in which fashion has an important role. In these short movies, fashion represents the driving force. It can be a character or the only protagonist, a symbolic value or something real; however, in each case, it is the movie's focus. 
But this is not enough to understand why we define this novelty as revolutionary.

A company's documentaries about a brand's history or manufacture are exceptions; the reporting style is often far from that used in creating an imaginary, which is what we are interested in.

Fashion films are the first specific type of fashion communication that was created to describe a brand's imaginary on the Internet.

For this reason, it is a mix and match genre using fashion, cinema and the Internet.

First of all, Fashion. Fashion is a language, as the designer interprets and translates a societal idea using forms. Fashion images have, additionally, been created. Photographers contribute to defining a new imaginary for the fashion world. Thanks to talented fashion image-makers, fashion can be seen as illustrating the evolution of the human body and the soul in a constant and everlasting flux. From the beginning, fashion photos have created their own world, interpreting in diverse ways an apologia of image, glorifying the harmony of shapes and the creation of an imaginary, creating exotic (especially from the past) and luxurious worlds. Nowadays, this diversity still exists and informs fashion films, which offer formal perfection of a fashion style and a web style along with fantastic imagery.

The cinema. Pasolini (1972) stated:

Cinema has a double nature...it is both objective and extremely subjective (to such an extent that it reaches an unsurpassable and awkward naturalistic fate)

This double nature reflects the double nature of fashion. Fashion has the objectivity of the present and the subjectivity of the creator and user.

Cinema and fashion lived and grew up together, as clothes are important tools for describing and showing the personalities of a film's characters. On the other hand, many fashion brands create a legendary story, similar to cult movies, recalling Givenchy in Breakfast at Tiffany's, or Giorgio Armani in American Gigolo. The world of cinema meets the world of fashion on the red carpet during cinematographic events, such as the Oscars, Golden Globes or other festivals. We think about the image of Liz Taylor wearing Christian Dior for her Oscar in 1961, Jane Fonda wearing a black suit by Yves Saint Laurent at the 1972 Oscars or Angelina Jolie wearing Atelier Versace.

Film language is also used to create fashion films. Old static fashion images move again and create new fashion tales in short movies. Fashion film is the natural evolution of fashion photography and is a new tool for reporting new fashion tales.

Fashion film also works by using time. Time imposes a connection between many images, creating a cause-effect relationship. What is after is justified by what is before, even if images are only evocative and suggestive and do not enhance a story.

Furthermore, fashion film uses sound, as spoken parts, or music, as in a movie. Music is an important element for increasing engagement by the consumer.

A fashion film may tell a story or it may show forms as in a harmonic movement, exactly like in a movie. In both, the power of dynamic images creates a new dimension that I call fashion in wonderland.

The Internet. Communication flow has changed and is now more active for fashion brands with the widespread availability of the Internet. More and more forms of content are available on multimedia, and the messages are interactive because they not only provide opportunities for feedback but also stimulate feedback, and the consumer becomes a co-author in creating the message. The process of convergence of media is like a river during a flood, which is not easy to control. Watching a movie on a smartphone or listening to a radio 
programme on an iPod or reading a newspaper on an I-Pad are everyday activities. Furthermore, the new media have become self-media. The world is populated by thousands of directors, reporters, cameramen and non-professional writers who autonomously produce all types of communication using the proper tools.

This does not mean that traditional media are no longer present in the communication panorama of today's society, but they have somehow adapted by creating a dialogue with the consumers using the same new media. Many television and magazine advertising campaigns refer to webpages. Backstage video of the campaign (for example, on youtube.com) that is occasionally presented by the company's Art Director or CEO can often be found on the Internet.

Finally web 2.0 is a synonym for social networks. It is a communication phenomenon; the internet has become a place to meet without borders and constraints, where all are equal and have the same power. The brand and consumer have practically the same authority. In fact, if a disequilibrium in weight were to be identified, it would be in favour of the consumer. Many fashion bloggers have authority that has been acknowledged by the industry's greatest opinion leaders.

The web is the birthplace of fashion film. As stated above, fashion films have been created for the Internet. New storytelling and new codes produce what I call the fashionnet-aesthetic.

New storytelling means that a fashion film can picture open stories. These fashion tales sometimes have a beginning, but often they do not have a clear end. They show a situation, a moment or just a moving photo of fashion in a wonderland. The most interesting fashion films are cryptic, strange, evocative and sometimes hyperbolic. They feed the new fashion world.

Another important aspect of fashion films is timing, as they must be short. As everything is quicker now, the Internet must be fast, as people do not pay much attention when surfing the net. In addition, entertainment is the main goal of a brand on the Internet and reaching this goal is possible if brand communication is short, eclectic, changeable and unexpected; a fashion film has all of these features.

Moreover a fashion film is a way to share special suggestions and emotions among fashion-conscious consumers and fashion lovers. Sharing is the greatest opportunity offered by the Internet, creating new and free net-tribes of people who love the atmosphere and love fashion in a wonderland, as well as the magic world of the fashion mood.

This said, what does fashion net-aesthetics mean and how does it work?

Aesthetics is a branch of philosophy that studies the meaning of shapes. Fashion net-aesthetics are those elements that produce meaning through form. Fashion net-aesthetics was created for fashion films.

It works using three different types of language. The term language is used because language is a system of codes, symbols and rules that create communication.

Languages created for cinema are now living a new life on the Internet.

They are: (1) productive language; (2) reproducing language; and (3) metaphorical language.

Productive language. The definition of productive language is related to the history of cinema, particularly to Sergej M. Ejzenštejn (1898-1948) and the Soviet cinema of those years in general. Ejzenstejn taught us to create a spontaneous connection among movie frames and look for meaning, even if the images do not have a clear connection. For example, if I am watching a house and see a woman in a flat, I am forced to think that the woman is inside that house.

Editing productive language creates significance by putting different images close together. Editing becomes the real centre of an Ejzenstejn film. The approach puts the stylish logic first, which may sacrifice the 
connection with reality. The main aim was to show an interpretation of reality and not actual reality.

Editing productive language in a fashion film produces brand content. Images may be real and evocative. However, what is really relevant is that the focus is on each single frame and not on the narrative plot. Thus, each photo is an independent unit that can live by itself. In fact, these frames are often used for advertising campaigns in fashion magazines.

An excellent example is the Secret Garden-Versailles, four episodes of the Dior saga. The first three episodes were filmed by Inez van Lamsweerde and VinoodhMatadin, and the music was performed by Depeche Mode. The only film differing in this Dior saga was the fourth chapter, which was filmed by Steven Klein in the château and gardens of Versailles to the soundtrack of the singer's intro to her eighth studio album, Only If for a Night. Nevertheless, the narrative plot in each episode is difficult to discuss because the images are presented quickly and are not necessarily linked to each other. The viewer can try to find meaning, but each frame can stand alone and create its own meaning. Many of these single Dior images were used as advertising campaigns in fashion magazines.

Reproducing language. The reference is to American editing or classic decoupage: the scene is divided into frames and the narration speaks about the image. Showing a discussion between two people becomes the focus. A reverse angle matching cut, axis cut, direction matching cut, glimpse and deleting the discontinuity are some of the techniques used. Editing was used to create the necessary connections to understand the story.

D. Griffith (1875-1948) was the first American cinematographic author who brought great American themes to film, such as the patriotic The Birth of a Nation (1914). His editing was called narrative editing, because it soldered and organised the spaces of the shot chosen for the narration. The total film structure creates narration. Adding details (e.g., close ups vs. long shots) enhances emotion and creates a dramatic feeling.

A. Bazin (1961-) defined this as invisible editing based on temporal continuity; events have a cause-effect relationship and the movie seems (only seems!) to be an open window into the world.

Reproducing language in fashion films creates a fiction of the real or imaginary world, and editing is typically cinematographic. Splitting an action scene into frames is subordinate to storytelling, even when it appears illogical or surreal.

A very interesting example is the Prada saga, named The Postman Dreams by Autumn De Wilde, which includes five episodes (The Postman, The Makeout, The Battlefield, The Tree, and The Laundromat). The main idea is possession like obsession and the absolute protagonist is the Prada Galleria Bag. This imaginary world is animated by childhood desires and mature fantasies, using reproducing language. For example, in The Tree episode, the protagonist is a woman crossing an open landscape on a motorcycle, and she arrives near a tree where there are red Prada Galleria Bags instead of red apples. She takes one of these bags and we hear the sound of a motor. The woman is on the back of the motorcycle and turns her head toward the source of the sound; the postman appears in his strange vehicle from the same side of the monitor. The story is surreal but the language is reproducing. The series is an ode to the playfulness of a particular style of American cinema (similar to the Wes Anderson style) and the inventiveness of fashion visionaries who understand what it takes to deliver. The duration is about $1 \mathrm{~min}$ for each episode, and each story shows a simple and short situation but is strongly connected by the over-riding value of this sequence. Thus, the Internet medium is being used to animate fashion in a wonderland.

Metaphorical language. In this case, fashion images work on image more than an imaginary, but lose contact with reality in a virtual way. Some inspiration can be found in Man Ray's images of the 1930s and 
in the 1970s with Optical Art or Op Art created by Victor Vssarely, which was contrasted with Pop (Popular) Art.

In particular, the film and photographic poetry of Man Ray was marked by a continuous tension towards linguistic experimentation. As a militant of Dadaism and surrealism, photography was both a means and a subject for Man Ray. In Le Retour à la raison (Return to Reason), the artist extended the rayograph technique to moving images. He sprinkled salt and pepper onto a piece of film and pins onto another and added night shot sequences taken at a fairground, as well as a segment showing a paper mobile dancing with its own shadow. What we see is far from reality, as this movie creates a new virtual dimension, where objects are alive.

While Pop Art was an artistic experience of the 1960s and 1970s that aimed to celebrate single objects and behaviours (behaviourism), Op Art offered a more analytical dimension of images, as in the Responsive Eye, which was the name of an exhibit at the Museum of Modern Art of NY in 1965, where the name Optical Art was created. Op Art strived to make images visually appealing by searching for formal perfection, and objects constituted a chance to experiment with the expressive possibilities of an image. Nowadays, $O p$ Art refers to any type of image, either static or moving, that works with optical illusion.

The metaphorical language in fashion film is not referential but a metaphor of something that is not clear and creates an optical illusion, so the viewer is pushed to get lost in them. The focus is on aesthetic pleasure when the atmosphere is dark, distressing or even ugly. Editing is often experimental to engage the emotions. These authors have used new technologies to create special effects and produce a virtual reality, which is what new consumers prefer nowadays.

As in Man Ray or Op Art, language is focused on the oneiric power of the shapes and on the possibility of communicating without story-telling.

In contrast with the past, today's fashion films are very short and speak the same language as computers, so we are thrown into a virtual game world.

An excellent example of these fashion films is ShowStudio, The house of Fashion film:

Established in November 2000, SHOWstudio's innovative and ground-breaking projects have defined the manner in which fashion is presented via the Internet. SHOWstudio has pioneered fashion film and is now recognised as the leading force behind this new medium, offering a unique platform to nurture and encourage fashion to engage with moving image in the digital age. ${ }^{1}$

SHOWstudio represents the most interesting company creating fashion films, using this type of language, with an avant-garde vision.

Nick Knight worked with Alexander McQueen and created excellent fashion movies. More recently, Ruth Hogben, who collaborates with Nick Knight in Showstudio.com, created several fashion films working with Gareth Pugh, the young British fashion designer.

We recount one of these futuristic projects:

With a collection inspired by religious iconography and Florentine opulence, Gareth Pugh made his Italian fashion debut at Pittilmmagine \#79. Showcasing his clothes via a unique fashion film, created with Ruth Hogben and projected onto the ceiling of a 14th-century church, Pugh melded the grand traditions and art of this ancient city with his own hyper-modern fashion vision. ${ }^{2}$

\footnotetext{
${ }^{1}$ Retrieved from www.SHOWStudio.com/about.

2 Retrieved from www.SHOWStudio.com.
} 
This choice was revolutionary because he went to Pittilmmagine only with a video, and this video was highly innovative in a very traditional context. Even the most progressive view is linked to the rapture of these images; the bodies come out in the dark, but they are not real, they are only forms of movement, drawing new shapes, thanks to the clothes. We are thrown into a virtual dimension where images are not referential but metaphors of a state of mind.

These images prove the great strength of fashion and attract the public because of the continual research that is going on to be always new and break rules.

In conclusion, each of these three styles contributes to produce this revolutionary new genre in fashion communication called fashion film, which is enriching fashion language.

This is why we say that fashion today is entering a new stage by creating its own world and providing new imagery to the consumer: so nowadays fashion lives in Wonderland thanks to fashion film.

\section{Rational}

Fashion Film is the new communication format that is typical of the fashion world; it was born on line and the web has incresed its diffusion in these last years.

Our main question is this one: How Cinema, Fashion and the Net work together, producing new aestethics, new language and new rules of communication in fashion market.

It's clear that Fashion Filmand the new power of fashion images in movement build up new brand experience with the net-consumer, using the old cinematographic language and the newest medium. The result can be reallyvisionary.

There are many different types of fashion film, using different codes and creating new languages and we are going to analyse them.

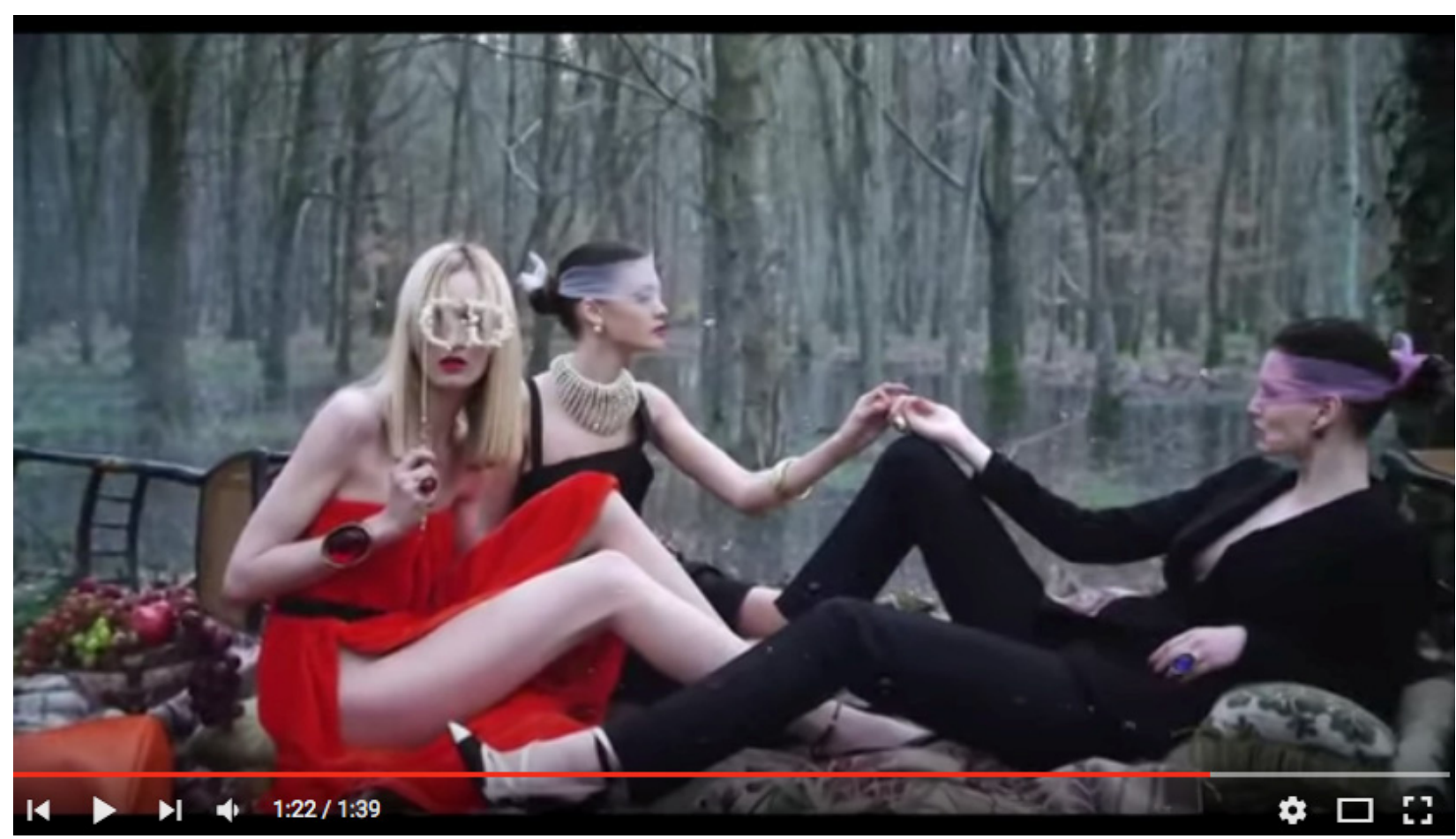

Figure 1. Dior - Secret Garden-Versailles, 2013 by Inez van Lamsweerde and VinoodhMatadin. 


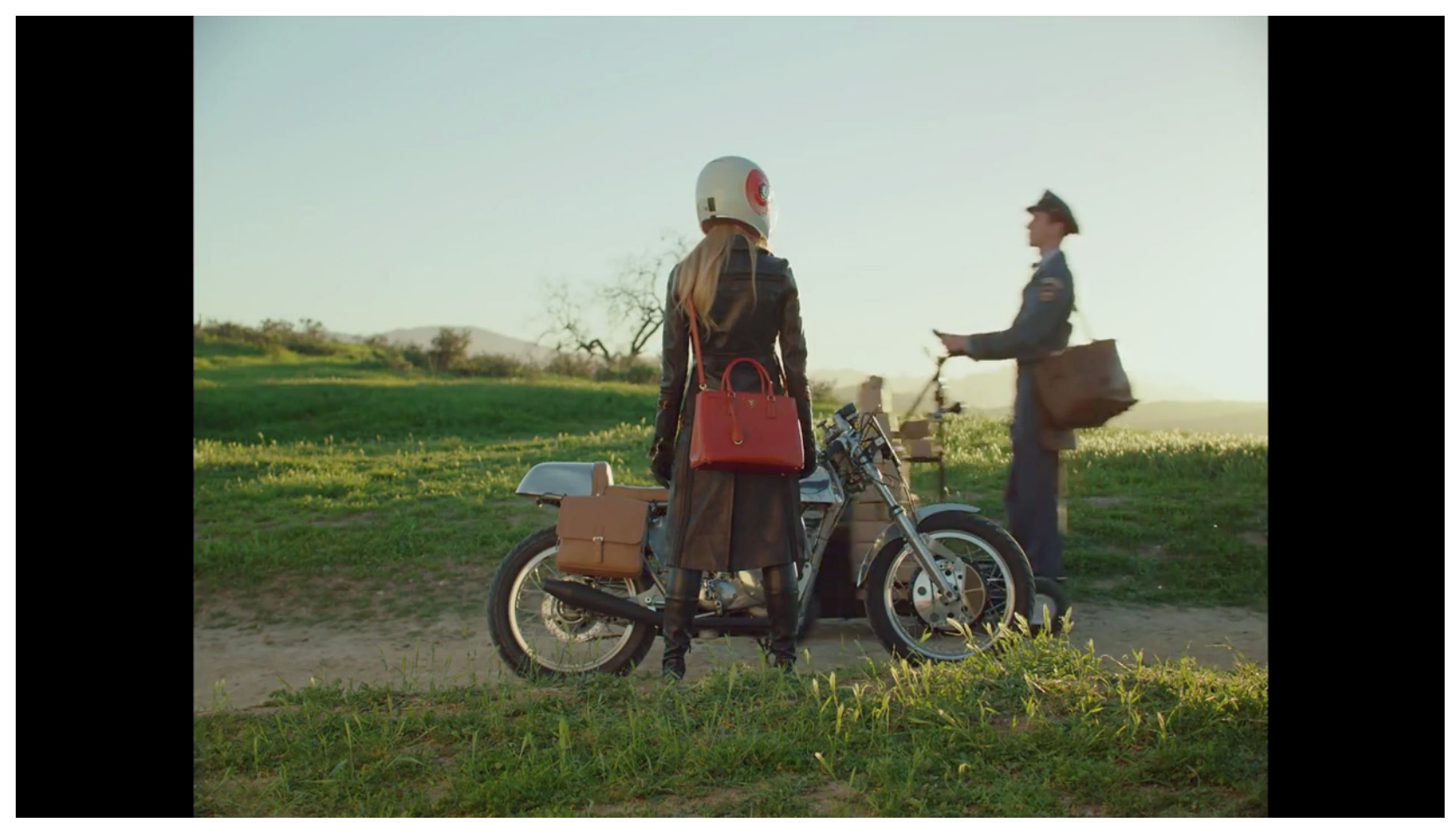

Figure 2. The Postman Dreams by Autumn De Wilde. Episode: The tree.

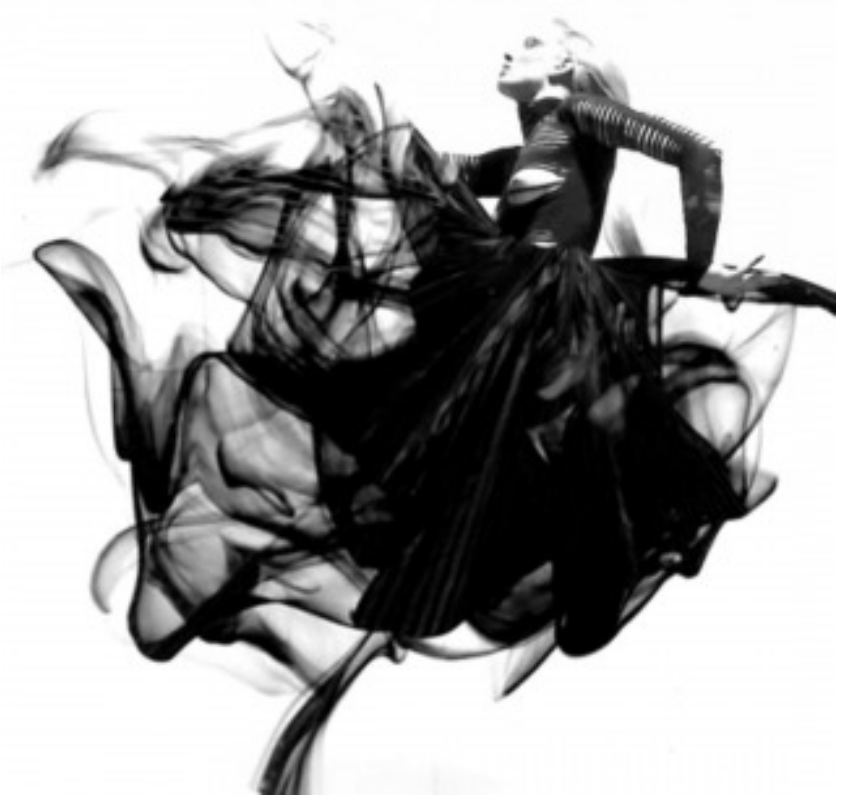

Figure 3. SHOWStudio: Gareth Pugh F/W 2009 by R. Hogben.

\section{References}

Eco, U. (1979). Lector in fabula. Milano: Bompiani Editore.

Escalas, J. E. (2009). Self referencing and persuasion: Narrative transportation versus analytical elaboration. Journal of Consumer Research, 33, 421-429.

Fabbris, G. (2008). Societing. Milano: Franco Angeli Editore.

Greimas, A. J. (1970). Del senso. Milano: Studi Bompiani. 


\section{FASHION FILMS AND NET-AESTHETICS}

Greimas, A. J. (1983). Del senso2. Milano: Studi Bompiani.

Phillips, B. J., \& McQuarrie, E. F. (2010). Narrative and persuasion in fashion advertising. Journal of Consumer Research, 37(3), 368-392.

Rhodes, A., \& Zuloago, R. (2003). A semiotic analysis of high fashion advertising. International Journal of English and Literature (pp. 11-16).

Schmitt, B. H. (1999). Experiential marketing: How to get customers to sense, feel, think, act and relate to your company and brand. New York: The Free Press.

Schmitt, B. H., \& Simonson, A. (1997). Marketing aesthetics: The strategic management of brands, identity and image. New York: The Free Press.

Wang, J., \& Calder, B. (2006). Media transportation and advertising. Journal of Consumer Research, 33(2), 151-162. 